
\title{
$\begin{array}{ll}\text { Research Square } & \begin{array}{l}\text { Preprints are preliminary reports that have not undergone peer review. } \\ \text { They should not be considered conclusive, used to inform clinical practice, } \\ \text { or referenced by the media as validated information. }\end{array}\end{array}$
}

\section{How Does Railway Respond to COVID-19 Spreading? - Countermeasure Analysis and Evaluation around the World}

\author{
Yonghao Yin \\ Central South University https://orcid.org/0000-0003-4208-2676 \\ Dewei Li ( $\sim$ lidw@bjtu.edu.cn) \\ Beijing Jiaotong University https://orcid.org/0000-0003-3738-029X \\ Songliang Zhang \\ Beijing Jiaotong University https://orcid.org/0000-0002-8526-5774 \\ Lifu Wu \\ Beijing Jiaotong University https://orcid.org/0000-0003-2614-9324
}

\section{Research Article}

Keywords: COVID-19 transmission, Railway respond, Countermeasure evaluation, Public health

Posted Date: November 13th, 2020

DOI: https://doi.org/10.21203/rs.3.rs-107167/v1

License: (c) (i) This work is licensed under a Creative Commons Attribution 4.0 International License. Read Full License

Version of Record: A version of this preprint was published at Urban Rail Transit on November 13th, 2020. See the published version at https://doi.org/10.1007/s40864-021-00140-z. 


\section{Abstract}

The global pandemic of COVID-19 has a significant impact on world development. As an important part of public services, the rail transit requires effective response countermeasures to control the spread of COVID-19. On the premise of considering the current development of the epidemic situation, this article discusses the characteristics of the COVID-19 transmission and finds out the vulnerable spot of preventing and controlling the spread of the epidemic in the rail transit system. The countermeasures that adopted to prevent COVID-19 spreading are analyzed from the external and internal categories, which were classified by 6 aspects: passenger service, cases care, information, staff, equipment and operation management specifically. Meanwhile, an evaluation architecture was constructed, which were established from the views of effectiveness, economic efficiency, acceptability, privacy and so on. The implementation effect of the measures was evaluated and the advantage and shortage of them were analyzed, which can be used to guide the epidemic prevention and control for the rail transit systems of the countries around the world in the future. It is meaningful to formulate a reasonable work schedule according to local conditions, providing a reference for rapid response to future public health emergency of international concern.

\section{Introduction}

With the outbreak and continuous spread of the global outbreak of COVID-19, as of Jul 13, 2020, a total of over 13,000,000 COVID-19 cases have been confirmed globally, with a cumulative number of deaths of over 560,000 cases. Fig 1 described the cumulative confirmed cases of COVID-19 around the world since March 1, 2020, as of July 26, 2020. The World Health Organization (WHO) had declared COVID-19 as a global epidemic. Considering the epidemic cannot be eliminated in a short time and small-scale interpersonal transmission of the virus may appear all over the world in addition. At the same time, the virus is always at risk of mutation. How to deal with such a global public health emergency has become a major global challenge that needs to be addressed by all countries around the world.

After the outbreak of COVID-19, different countries all over the world took urgent measures to cut off the transmission of the virus. People gathering, movement and transfer may cause the spread of the virus from person to person, so it is necessary to close or control public places and reduce the mobility strictly. The traffic and transportation industry are responsible for the emergency transport of materials for epidemic prevention and control, on the other hand, it can lead to the spread of COVID-19 as transferring a large number of passengers in closed vehicles within a period of time. As railway is a high-density traffic mode, it is a great challenge to control the spread of the virus via rail traffic while maintain the basic level of service, let alone guarantee the operation profit of railway operation companies. With the continuous increase of the travel speed, the spread of the virus become more and more fast by rail transit. Although many countries have tried various countermeasures from encourage passenger to wear masks to reduce the gathering of passengers on platform. The question of "what kind of countermeasures should be taken during the pandemic" remains opening.

Despite very limited research in COVID-19 spreading prevention, a few of research can be found from another virus pandemic. International Ebola Response Team et al. (2016) presented analysis of data collected during the Ebola epidemic in West African and highlighted parts where control could be improved [1]. Kramer et al. (2016) predicted the spread of the Ebola epidemic through assessment. Due to the characteristics of dense traffic and closed space, the range of transmission of the virus can reach 4.5 meters in public transport. And it is more likely to have cluster cases in public transport. As a result, in the field of transportation, how to control the spread of virus is also an important topic [2]. Colizza et al. (2006) studied the role of air transport networks in determining the global spread patterns of emerging disease [3]. Zhao et al. (2020) discussed the relationship between train transportation and the spread of COVID-19 in a data-driven way [4]. Tirachini et al. (2020) outlined the measures to reduce crowding in public transportation [5]. Zheng et al. (2020) examined correlations of daily frequencies of each transportation methods and the distance between Wuhan and other cities, with the daily number and the cumulative number of COVID-19 cases. They emphasized that strong preventive measures should be taken in cities with shorter distances and more frequent public transportation connectivity with epicenter to contain the COVID-19 epidemic [6]. Chu et al. (2020) investigated the effects of physical isolation and the use of masks and goggles on the spread of the virus [7]. Hu et al. (2020) discussed the risk of COVID-19 transmission in train passengers. They found that the transmission risk is heterogeneous depend on co-travel time and seat location, and the passengers adjacent to the patient have highest risk. Therefore, some measures should be taken to prevent the virus transmission in the rail transit system [8].

As a part of public transportation, how to prevent the spread of COVID-19 in rail transit is also a key concern of government transportation departments. Due to the different national conditions such as the culture, economy, social education level etc., the traffic response to the epidemic also varies. Practice shows that the isolation of infectious sources, active treatment, public cooperation and other methods may effectively control the spread of the epidemic. While some countries are worrying about the possibility of bankrupt of railway companies and the potential negative influence on economy and society. Given that many countries (such as French and Brazil) are still in the outbreak phase, it is important for different countries to share their experiences in the global response to the outbreak, the full resumption of production and the future development of epidemic prevention plans.

The objective of this study is to review and assess the current countermeasures been taken in the railway field around the world. This paper summarizes the countermeasures taken by the railway operators from various countries to deal with the outbreak of COVID-19 from the aspects of external management and internal management. External management includes information dissemination, passenger service and suspected case handling, while internal management includes employee management, equipment management and operation management. Finally, the evaluation indicators are established to response to the epidemic and evaluated to compare the advantages and disadvantages of them, which provides suggestions for countries to better fight the epidemic and respond more quickly to public safety emergencies in the future.

\section{Spreading Of Covid-19 Through Rail Transit System}

To introduce effective policies for the railway industry, it is necessary to have a discussion for the transmission mechanism of the virus and the operational characteristics of railway. Afterwards, the relationship between virus transmission and rail transit system operation will be focused and the vulnerable spot 
can be found out.

\subsection{The characteristic of COVID-19}

COVID-19 caused by virus named SARS-CoV-2. It is the third new coronavirus that has been found in humans across species in the past 20 years. The first two were SARS (Severe Acute Respiratory Syndrome) in 2003 and MERS (Middle East Respiratory Syndrome) in 2014.

Chen (2020) found that the virus (SARS-CoV-2) is not stronger than SARS, either from the fatality rate or R0 (R0 implies the basic reproduction number in epidemiological, referring to the average number of people infected with an infectious disease by a person who is infected with an infectious disease without external intervention under the circumstance that no one is immune. The larger the R0 number, the harder it is to control an epidemic.) [9]. However, it is more infectious than Ebola Virus and Middle East Respiratory Syndrome (MERS), which means that there are more confirmed cases of SARS-CoV-2. But overall, the current new coronavirus appears to be relatively low pathogenic and moderately contagious. Table 1 shows fatality rate and R0 of common viruses all over the world. In the context of economic globalization, there is a high probability that the virus will spread around the world. If the supervision is negligent, local outbreaks may take place.

Table 1. Common viruses and corresponding fatality rate and R0.

\begin{tabular}{ccc}
\hline Virus name & Fatality rate & R0 \\
\hline SARS-CoV-2 & $3 \%$ & $1.4-5.5$ \\
SARS & $10 \%$ & $2-5$ \\
MERS & $40 \%$ & $<1$ \\
Measles Virus & $0.3 \%$ & $12-18$ \\
Ebola Virus & $70 \%$ & 2.3 \\
HIV & $80 \%$ & 3.4 \\
\hline
\end{tabular}

\subsection{The transmission characteristics of COVID-19}

\subsubsection{Clustering}

The cluster outbreak of COVID-19 refers to that, it will be judged as a cluster outbreak if there is a confirmed case found in the family, shopping malls, parties, construction sites and other places. It is also the same as more than 2 cases were diagnosed as COVID-19 infection pneumonia or suspected cases due to close contact in 14 days.

Most of the cluster outbreaks occur on vehicles (planes, trains, cars, buses, etc.) and in families. Hospitals, offices, service areas, railway stations, trains, ships, construction sites, enterprises and other places are the focus of prevention of clustered outbreaks. The number of cases on the Diamond Princess, which is a cruise ship docked in Japan, is numerous because the ship is a means of transport in confined spaces. And on August 2, 2020, the Norwegian Institute of Public Health announced that at least 41 of the passengers and crew on a Norwegian luxury cruise ship had been tested positive, which also resulted from clustering infection. Up to August 18, 2020, there have been a number of cluster cases in America, Australia, Canada, China, France, Japan, etc.

\subsubsection{Virus survival time}

Experimental results have shown that the COVID-19 virus can survive for up to 72 hours on plastic and stainless steel, less than 4 hours on copper and less than 24 hours on cardboard. In environments with higher humidity aerosols, COVID-19 virus can also survive for more than three hours. As a result, once the virus appears in train carriages, stations and other crowded and fluid closed environments, its survival time is so long enough to cause thousands of people to be infected [9].

\subsubsection{Transmission routes}

The main transmission routes of COVID-19 are droplet spread, contact transmission and aerosol propagation.

Droplet spread. The disease spreads primarily from person to person through small droplets from the nose or mouth, which are expelled when a person with COVID-19 coughs, sneezes, or speaks. These droplets are relatively heavy, do not travel far and quickly sink to the ground. People can catch COVID-19 if they breathe in these droplets from a person infected with the virus. An advice from Centers for Disease Control and Prevention (CDC) notes that COVID-19 spreads mainly among people who are in close contact (within about 6 feet) for a prolonged period [10]. Therefore, it is necessary to keep a safety social distance (at least 6 feet or 2 meters) from other people who are not from your household in both indoor and outdoor spaces.

Contact transmission: Droplets can land on objects and surfaces around the person such as tables, doorknobs and handrails. People can become infected by touching these objects or surfaces, then touching their eyes, nose or mouth. This is why it is important to wash hands regularly with soap and water or clean with alcohol-based hand rub.

Aerosol propagation: If the infected person is in a confined space, the virus is very easy to aerosolization and form biological aerosols, resulting in the virus survive and transmit through the aerosol [11].

\subsubsection{The risk level of areas about COVID-19}

Because the severity of the outbreak varies from region to region, the responding strategies should vary according to the different conditions of the regions. Therefore, it is necessary to grade the risk of different regions according to the situation.

Take China as an example, according to the actual situation and development trend of the epidemic, comprehensively considering the number of new and cumulative confirmed cases and other factors, the country is divided into low-risk areas, medium-risk areas, high-risk areas by county urban units. 
(1) High-risk area: there are more than 50 cumulative cases occurred within 14 days.

(2) Medium-risk area: there are new confirmed cases within 14 days, the cumulative number of confirmed cases does not exceed 50 , or the cumulative number of confirmed cases exceeds 50 cases, and no concentrated outbreak occurred within 14 days.

(3) Low-risk area: there are no confirmed cases or no new confirmed cases for 14 consecutive days.

Fig 2 shows the risk level of the outbreak in Hubei Province of China on February 28, 2020. The red regions are high-risk areas, the yellow regions are mediumrisk areas, and the green regions are low-risk areas.

\subsection{COVID-19 transmission and rail transit}

\subsubsection{External threats}

(1) Input source

As one of the most crowded public places, the rail transit system is visited more than million times per day by the passengers. Therefore, the input source of the system should be strictly controlled to prevent the spread of the epidemic, which is one of the weakest vulnerable spots of the system. Specifically, the passengers should be strictly screened before they entering the station, such as taking temperatures, asking about the travel track and so on. Meanwhile, the passengers are also suggested to equip personal protection, such as wearing masks, and washing hands frequently and so on.

(2) Gathering of passengers

The passengers will arrive at the busy stations frequently and intensively in a short period of time during peak hours, which may lead to the gathering of passengers because of the process of security checking, card swiping and passage walking. Meanwhile, passengers are also gathering at the hall and platform of the stations when they are eating at restraints, buying goods at stores, going to the toilet, resting at the waiting room, boarding the train. In addition, the passenger density is quite large in crowed carriages. The droplets transmission and contact transmission will become the main means of virus transmission in rail transit system when a large number of passenger flow gathered with possible cases. The distance between passengers is so close for the virus to spread widely. Therefore, the passage, hall, platform, and carriage should also be considered to keep the safety social distance between the passengers, which may decrease the risk of epidemic spreading effectively. Controlling passengers in a safety social distance and setting train seat distance reasonably are the main measures to deal with external hazards at station and on board.

(3) Risk level of public areas in railway system

Due to the facilities are used with different frequency, the contact frequencies of passengers are different, and the risk level of these public areas are different too. The facilities that are frequently used are the vulnerable spot of the system, in which should be focused to prevent the spreading of the virus. Based on the facilities' frequency of usage, the public areas should be classified as different level of risks. For example, at Beijing South Railway station in China, the public areas in the railway system are classified as three risk levels. The turnstiles, escalators, and security check facilities are almost used by every passenger, and the toilet areas are bacteria-infested. These facilities and areas have a high frequency of usage and very necessary for most of the passengers, which should be classified as the high-risk public areas. The ticket windows, seats at the waiting areas, vending machines, restraints and convenience store are usually used by most passengers but can be avoid if they want. These areas can be classified as the medium-risk public areas. The telephone booths, gift stores and inquiry desks are seldom visited by passengers, which can be classified as the low-risk public areas. Correspondingly, the preventive measures against epidemics should also be different for the public areas with different risk levels, such as the disinfection frequency.

\subsubsection{Internal danger}

\section{(1) Sealed carriages}

As a long and narrow closed container, the rail transit vehicle is isolated from the outside, which changes the air only through the ventilating system. In the closed places of rail transit trains, saliva and other respiratory droplets can easily spread from patients to healthy person. Therefore, the railway ventilation system is the key facility to prevent the spread of virus. Improving ventilation system, keeping the sewer clear and paying attention to environmental disinfection are important means to prevent the outbreak and expansion.

\section{(2) Working environment}

Since the staffs are working in the same environment as high-traffic passengers, and the staffs are avoid contacting with the passengers closely, the virus may spread more rapidly within employees. As a result, the measures such as strengthening staff protection, decentralizing staff distribution and restricting entry for regions are also necessary.

\section{(3) Operation plan}

According to preliminary statistics, during the outbreak in China, from January 23 to February 10, 2020, the average daily passenger traffic of Chinese urban rail transit (except eight cities that were all suspended) decreased by about $70 \%$ to $90 \%$ compared with the same period in 2019 . On February 10 , after some enterprises resumed work, the average daily passenger traffic of urban rail transit has rebounded. Among that, passenger traffic of Beijing, Shanghai, Guangzhou and other cities increased by about $72 \%, 99 \%, 48 \%$ compared to the resumption of work [12]. With the gradual resumption of work and production 
in many provinces and cities, the potential growth pressure of passenger flow is enormous. It is also a great challenge of making a well-planned operations plan, optimizing transportation processes, and cooperating closely with the outside world.

\section{Countermeasures Adopted To Prevent Covid-19 Spreading}

The rail transit system needs to take a series of countermeasures to reduce the virus infection risks of public transportation and control the spread of COVID19 , because of the leakproofness of the system and the dangerousness of the infectious diseases. As an external service department, it should adjust the train service, focus on the management of internal staff, and inform the common sense of epidemic prevention for users.

As the worldwide professional association representing the railway sector, International Union of Railways (UIC) has published two questionnaires in 2020 March to survey the countermeasures that adopted to prevent COVID-19 spreading in the rail transit system. There are 57 organizations from 35 countries around the world participated in that survey, which are the members of UIC. A data base file named UIC Covid19 TF_Data Base is proposed by UIC, which recorded the countermeasures in those countries to prevent COVID-19 spreading in rail transit field [13].

Based on the survey of UIC, the countermeasures of rail transit systems in different countries around the world are collected and collated, and the outline of the epidemic prevention initiatives is shown in Fig 3. The countermeasures are classified as 2 categories, 6 aspects, and 31 items. Specifically, from the view of management scope, the measures are divided into the external and internal management countermeasures, and every category have 3 aspects, which will be discussed in detail as follows.

\subsection{External epidemic prevention and control for rail system}

Rail transit system provides basic guarantee for mobility of society and it is necessary to protect passengers' life and health. The spread of the virus should be controlled in the process of organizing passengers and detailed measures should be developed to deal with suspected cases. In addition, due to the public attribute of rail transit, media resources are accompanied by it, which can be considered as a window for information sharing. Therefore, the external management countermeasures include three aspects: passenger management, COVID-19 suspected cases disposal, and information dissemination.

\subsubsection{Service management}

In the rail transit system, passengers need to go through a series of processes such as enter the station, wait the train, board the train and exit the station. In some countries, passengers should be checked the at security passage before they enter a station. If effective measures are not taken in the process, the moving passengers, crowd platforms and closed carriages are very likely to cause the spread of the epidemic. As the train is a movable equipment and the station is a fixed place, the epidemic prevention and control measures should be adapted to different environments. Therefore, the passenger control and service measures on board and at station will be analyzed independently in this section.

(1) On board

The train is a moving device, which is a closed environment during operation, so the coronavirus will spread quickly in the limited space once it invades. In addition, passengers need to stay in the carriage for long time during travel, which may greatly increase the duration of exposure to virus and the risk of infection. Therefore, some necessary preventive measures should be taken on board.

Loading rate control. To encourage passenger to maintain safety social distance, controlling loading rate of trains or occupancy seat are widely used in many countries, such as China, Canada, France, South Korea and so on. Because the primary way that COVID-19 appears to spread is by close person-to-person contact via droplets or skin touch. Keeping a safety social distance (approximately 6 feet or 2 meters) can prevent the spread of the virus. For example, the standing tickets are no longer sold in China during the outbreak. The train occupancy rate is limited at around $33 \%$ in Spain, $35 \%$ in Canada and $50 \%$ in China The passengers won't be seated directly beside one another, which are just seated in one seat out of two in France and South Korea. In Italy, some new rules for seat reservation are set, which ensure the minimum distance more than 1 meter.

Personal protection. The onboard passengers are required to take personal protection such as take masks, wash hands, limit close contact, cover mouth and nose when coughing or sneezing. Wash hands frequently is one of the cheapest and most important ways to prevent the spread of the virus. Regularly and thoroughly clean your hands with an alcohol-based hand rub or with soap and water, which can kill viruses that may be on your hands. The process of washing hands is important but easily neglected. Specifically, to eliminate the virus on our hands effectively, we should wash them for at least $20-30$ seconds and following a scientific procedure. What's more, the time of washing hands should also be noticed. After blowing nose, coughing or sneezing, after visiting a public space, after touching surfaces outside of the home, before, during and after caring for a sick person, before and after eating, we should all make sure to wash our hands [14].

Take temperature. Because one of the most typical symptoms of COVID-19 is fever, it's necessary for passengers to be screened the temperature on board. Considering that some passengers may pass the inspection by physical cooling before boarding, the onboard passenger will be randomly taken the temperature to timely find the suspected infection. Any passenger with body temperature of $37.3^{\circ} \mathrm{C}$ or above will be insulated immediately and then transferred at the next station for medical check.

Adjust catering service. The catering service is adjusted or even cancelled on the train. It is necessary to control the catering service to prevent the spread of the virus because passengers will take off their masks and eat. As a result, the prohibition use of dining car is advocated in some trains. Operators delivered all foodstuffs and beverages to passengers as a package and covered. Furthermore, all the glasses, plate, cutlery are single-used and disposable. 
Offer health necessaries. The operators provide protective equipment such as masks and bottled disinfectant for passengers to prevent the virus catching and spreading. To implement this policy, the crews provide free masks for passengers, if they lost their masks at station or on board, and the passengers are also suggested to take masks before they enter the station. What' more, the crews are asked to avoid physical contact and do not touch passengers' personal belongings wherever possible. The crews should also carry a disinfectant whenever possible, and managers are requested to arrange for disinfectants to be provided in their area of responsibility.

Improve waste disposal process. The used masks, tissue and other trashes may carry a lot of virus, so the disposal of the special trash properly is important. Waste may cause biochemical pollution, especially for masks and used tissue, so they should be put into a bag and then thrown away in the trash. The bags have been put in all compartments for travelers' hygienic rubbish. The bags are tightly closed and placed in the designated places when they start to be used.

(2) At station

To keep the passenger crowd level of the rail transit system within a preventable range, it is necessary to not only take measures on board, but also at stations to guarantee the service level for passengers entering the system. Meanwhile, the management of the station hall also cannot be ignored, which can cause crowds gathering. The specific measures are shown as follows.

Investigate qualification. Pre-boarding temperature screening measures can be performed to avoid the suspected patient access to public areas. The infrared automatic thermometers can be installed at major stations and all passengers' temperatures are taken at station entrance or exit. What's more, to protect the safety of passengers and staffs, the suspected patients are controlled and suggested not to board the train. This measure can ensure that most of the passengers of rail transit service are all healthy, which is efficient to control the virus spread at the source, even it may make passengers feel troublesome. Specifically, in China, the health quick response code (health QR code) is proposed by the government, which can reflect the health condition of a person. The citizens apply for the health QR code on the mobile phone application, and the health condition will be updated all around the country. If the citizens are patients or contacted with the suspected patients or stop at the area where is high-risk area, the health QR code will reflect the information with a red color; and if the citizens are suspected of contacting with the patients or stop at the area where is medium-risk area, the health QR code is yellow; otherwise, it is green. The passengers will be checked the health QR code when they entering the station, and only the passengers with the green code can get through. The passengers with other color codes are suggested stay at home and reduce the unnecessary trips.

Close public places. Just like the restaurant on board is closed, the operators closed the public places, such as restaurants, shops, and passenger waiting rooms of the stations, which can avoid the indirect contact with others, and reduce the passenger gathering.

Suspend ticket checking. In some railway systems, the ticket checking is mandatory before they get access to the platform. During the pandemic, the staff welcoming and ticket checking at station exits can be suspended or canceled to avoid unnecessary gathering of people and avoid the contact to protect staffs.

Provide travel advice. The operators provide some travel tips to passengers, which can help reduce the risk of viral infections. For example, ask passengers to wear masks, avoid walking into the crowed people, comply with minimum interpersonal distance, and not to eat food at stations.

Increase relief inventory. Since disinfection and cleaning have become daily routine tasks, the necessary material reserves are indispensable. The government should specifically introduce policies to guarantee the supply of disinfection and monitoring equipment and increase the stock of antiviral drugs. The mentioned materials include hand sanitizer, disinfectant, protective clothing and spare medicine. In addition, a certain number of masks should be prepared for passengers to prevent them from needing to be replaced if the masks fall or break.

\subsubsection{COVID-19 suspected cases care}

Suspected cases generally have the symptoms of COVID-19 without nucleic acid testing, such as cough, fever, shortness of breath or fatigue. If the diagnosis is confirmed after testing, they will be converted to a confirmed case. Passengers in this situation may also be contagious due to the presence of viruses. To minimize the risk of virus spreading, proper treatment of the suspected cases is required. The process of take care of suspected cases in the railway is very important and necessary in epidemic prevention and control. Based on the survey of the affected countries, a series of successive measures can be summarized.

Just like the management of passengers, the handling of suspected cases can also be divided into two circumstances: on board and at station. The circumstances of the two scenarios are different so the corresponding measures can also be diverse. Generally, the stations are in the urban area and have seamlessly connection with the medical department. As the result, measures for taking care of the COVID-19 suspected cases can be easier at stations. Meanwhile, the treatments on board may be complicated but the main process are similar. The main process of handling with the suspected cases is that: keep the suspected cases taking masks, set up a temporary isolation area, transfer them through the specialized access, transfer the close contacts to a safe place and observed regularly, report the information to the related units, record and trace close contacts. The specific measures of the above process are listed sequentially as follows.

Keep suspected case taking mask. To reduce the risk of infection for other passengers, the suspected cases are asked to keep taking mask. If the mask of the sick person lost, they will be given an unopened mask so they can take the mask themselves, and use the mask following the instructions in the information sheet.

Set up temporary isolation area. A temporary isolation area should be set up at a specific space of the train or the station. When the suspected cases are discovered by taking temperature, they will stay in the temporary isolation area until they are transferred. 
Report suspected case. The suspected case will be informed to the related units (such as the dispatching office or the centers for disease control) by the known reporting channel. The transfer measure and necessary coordination will be scheduled.

Transfer suspected case. The suspected cases should be transferred to the temporary isolation area the first time, which minimize contact with healthy people. Then, based on the communication with the related units and the transfer plan, the passengers with a fever will be timely delivered to the scheduled station with a health check-up station. They will be transferred to the local epidemic prevention department for further medical checks and treatment.

Transfer close contacts. The passengers in the sick passenger's immediate vicinity will be asked to move to a safe place and observed regularly. Wherever possible, prevent people from entering and leaving the area where the sick passenger is located. Meanwhile, the operator will provide guidelines for managing the suspected and infected individuals.

Record and trace close contacts. All people (including train crew) who came within 2 meters of the sick passenger will be distributed the forms (include identity, a means of contacting and so on) and requested to fill them out. After screening, if the fevered passengers are either confirmed or suspected patients, the operators will immediately inform the local epidemic prevention department and report information of their close contacts, to make it easy for authorities to trace them. Trace the infected person for infection process as clearly as possible. Meanwhile, the confirmed cases' information will be published and announced to the other passengers on the train. In addition, considering the mobility of people, this information should also be reported to the national unified information platform, in order to meet the need for big data search later.

\subsubsection{Information dissemination}

As a part of the public service system, the information system of rail transit such as broad casting, screening, sign etc. is one of the most important medium to disseminate information. When the outbreak occurs, the rail transit system plays significant role in providing travel and epidemic prevention information for passengers and citizens. As passengers may not understand on the different operation control countermeasures with normal situation.

Specifically, information disseminating measures can be classified into online measures and offline measures. The online measures include information disseminating by TV, official website, mobile app, social networks and e-mail. The offline measures include information disseminating through public announcement systems and staffs.

Release information using TV and internet. The operators continuously and timely updated the information related to the epidemic outbreak, updated on prevention measures, and organizational measures through online media tools such as TV, official website, social networks, mobile app and e-mail. Meanwhile, they disseminated the knowledge on the virus prevention and information regarding coronavirus to passengers, which includes the cause of the disease, symptoms of the disease, ways of transmission, control and prevention, etc.

Disseminate by internal mediums. The operators kept looping the promotional videos and voices of prevention measures with different languages through public announcement systems such as surveillance service, information display and broadcast at stations and onboard. Besides, some staffs were briefed on proper hygiene measures to support passengers.

Provide posters and materials. The operators published and provided leaflets, brochures and initiative materials to travelers to raise awareness among passengers regarding symptoms and hygiene practices includes information about symptoms, personal protective measures and social distancing measures. What's more, the posters about prevention information can be published at the bulletin board and the prevention measures poster was displayed on the bathroom doors, mirrors, ticket office and business lounge.

\subsection{Intemal epidemic management for rail system}

In addition to the prevention and control for passengers in the rail transit system, it is also very important to ensure the safety of the staffs. It is a requisite for the normal operation of the system, because a railway staff would connect with hundreds even thousands of passengers. One case of staff could cause severe spread of the virus in the network. The virus may remain at the surface of the equipment, in which the virus carriers touched. Therefore, the equipment in the rail transit system that includes trains and station communal facilities should be timely disinfected during epidemic period. What's more, the normal operation rules may also break, which need to adjust timely to accommodate the passenger demand during the specific period. The internal measures to ensure the normal operation of the rail transit system include the following aspects: Staff management, equipment management, and operation management, which will be discussed in detail as follows.

\subsubsection{Staff management}

The staffs can be regarded as virus-susceptible population, because they contact with passengers frequently every day especially for the trainmen and ticket sellers. Therefore, the measures for passengers are also apply for the staffs, such as take masks, take temperature before working, keep safety social distance and so on. Meanwhile, in allusion to the processes of shifting work, meeting and training, some special measures need to be taken to prevent and control during the epidemic period.

These measures are being taken by most countries, such as wearing masks, taking body temperature before working, reducing the distribution density of staff in the workplace, prohibiting fever people from taking jobs and distributing protective equipment for employees. In allusion to the processes such as shifting work, meeting and training, some special measures need to be taken to prevent and control during the epidemic period as follows.

Strengthen staff protection. To ensure the normal operation of the rail transit system, the health and safety of staffs should be protected firstly. As the general protection measures, wearing masks, distributing protective equipment for employees, reducing the distribution density of staff in the workplace, taking 
temperature before working and prohibiting fever people from taking jobs are effective for epidemic prevention and control, which are being taken by most countries. What's more, if the face masks are disposable, they should be replaced per 6-8 hours for the staffs on long duty [15].

Decentralize staff distribution. It will greatly avoid the contact between people because physical isolation can effectively cut off the path of virus from infecting staff. Considering the closure property of workplace, once an employee is infected with the virus, it will spread quickly in a closed space. Some measures should be taken into consideration to insulate the internal official area from the external environment, and decentralize the distribution of the staffs. For example, rail transit department may set up separate passages, elevators and toilets for employees to avoid sharing the same facility with passengers. To reduce the shift frequency, the staffs can be rearranged to change the working shift system. The staffs who may contact with the passengers are organized and managed independently, which can avoid that the internal staffs contact with the external people.

Encourage remote communication. Assembly is easy to cause people to gather infection, which often occurs in public places such as hospitals. To ensure the safety of staff, scenes where many people gather should be avoided as much as possible. Without face-to-face meetings, they can take the form of online office, which not only reduces the contact, but also makes the time arrangement more flexible. The companies encourage people to use the Internet and communicate by email. What's more, the private network is also the main medium for transmitting information by which some companies decided to release information.

Strengthen staff training. This method can improve the awareness of workers to prevent the virus. They should ensure their own health firstly before they serve others. As a working skill, it should be available for every employee. There are many countries taking action to train staff, but the content of training in different countries is slightly different. Specifically, it mainly includes the following four specific contents. First of all, let the staff master the management procedures for suspected cases and confirmed cases, which is a basic ability that the staffs should have. Furthermore, it is important for staffs to assess their health status. Once suspect to have symptoms by themselves, they should be quarantined at home in time to avoid bringing the virus into the workplace. In addition, they should also have sufficient knowledge of COVID-19 prevention and control. Not only to protect themselves, but also to improve the ability to identify the infected people. Moreover, some countries have adopted training to encourage staff to pay attention to work etiquette and personal hygiene.

Enhance work flexibility. In response to the special situation during the epidemic, employees may also encounter various difficulties correspondingly. To enhance the care for them and allow them to work on the job better at the same time, it is necessary to adjust the flexibility of daily work. Flexible work system could be attempted to implement, which has provided employees with a certain degree of freedom. Some companies minimize the number of workers in positions exposed to the outside world and strive for the health and well-being of employees. For employees who are in poor physical condition and have low immunity, special holiday is a favorable measure to provide employees with health protection. Due to the school closure in some place, many staff's children are left unattended. Therefore, some companies specifically allowed employees to carry their children to work and set up a special place for guardianship.

Advise staff to stay at home in spare time. In addition to regulating employees' behavior in the work process, if daily life is neglected, the virus will also be carried into the working place. As a public service industry, the healthy condition of the staffs in the system should also be strictly guarded during non-working times. Prohibiting employees from going to high-risk areas can greatly reduce the possibility of infection. On the basis of grasping the employees' disease history, more precise measures were promoted gradually, such as prohibiting employees from transiting at local airports in high-risk areas. The employees are advised to avoid going to the hospital or other crowded places. Last but not least, quarantining employees who travel to the high-risk areas is also an effective means.

Restrict entry for regions. Reducing the movement of people is the most traditional measure for epidemic prevention and control. Some places such as control rooms and ticket offices do not need to open for all staff, in which should be strictly limited the number of people who enter these areas. The operators in Japan and Belgium have set up some areas where unrelated people are not allowed to enter, and the channels of employees have been optimized to reduce the possible spread of the virus.

\subsubsection{Equipment management}

Facilities and equipment such as passenger station hall, platform, and trains, ensure the daily operation of public places, but they will also become a primary way for the virus to stay and spread while in contact with different people. In order to cope with epidemic situation, the use of equipment should also be adjusted accordingly for changes.

Enhance air circulation. The ventilation equipment inside the train have been reformed, the main purpose of which is to enhance the air circulation. The same situation also happened on the ventilation equipment of the station. As a respiratory disease, COVID-19 can spread through droplets. In a closed space, the virus will show greater lethality, when it reaches a certain concentration. Frequent ventilation is mainly to reduce the virus concentration. When fresh air circulates and the droplets carrying the virus fall to the ground, its pathogenicity will decrease and the chance of infecting others will be less.

Increase disinfection frequency. Basically, each country all over the world regularly disinfects every kinds of equipment in the rail transit system. From fixed equipment to mobile equipment and from the surface of the object to the whole equipment, it is necessary to arrange for dedicated personnel to perform killing virus and cleaning work. The disinfection operation mainly includes two levels, by fixed cyclical time and in specific location. The common disinfection areas at stations include security equipment, gate machine, elevator cars, seats, toilets, handrails and recycled ticket cards. The train should focus on the columns, armrests, seats, doors and other parts, which are easily accessible by passengers. Apart from that, air-conditioning filters should also be replaced regularly. The depot should also be all-round disinfected in the high-risk areas. The stations and vehicles should be disinfected and cleaned at different frequencies according to the level of area risk. In China, for example, the key equipment on the station that passengers used frequently such as toilet, ticket gate and escalator are disinfected per 2 hours for the high-risk areas (such as Beijing in June 2020); the hall and platform of stations in low-risk areas (such as Changsha in February 2020) are disinfected 2 times per day. What's more, except for the planned disinfection operations, the specific disinfection that 
response to the suspected cases care should also be considered. The space that suspected cases touched and remained should be disinfected on time. Meanwhile, the carriage where suspected cases stayed should be disinfected on time. As soon as the train arrives at the car depot, the whole train also should be comprehensively disinfected.

\subsubsection{Operation management}

The occurrence of COVID-19 has led to variation in the relationship between supply and demand. To meet the evolution of passenger travel, the operation service should be adjusted in a timely manner. The specific performances are as follows.

Adjust operation plan. The epidemic has drastically changed passenger travel demand. At the same time, it is necessary to consider the density and evacuation of personnel while transporting passengers. Especially for some countries which international passenger travels are frequently, the supply structure of the transportation system should be adjusted accordingly. In view of this situation, the external border services of rail transit ought to be shut down and the train stopping at some specific cities (high risk areas) should be directly canceled. Meanwhile, the passengers are informed about the risk of traveling and advised to travel during off-peak hours instead of crowding during peak hours. Reducing the frequency of train operation also proves to be a useful method. In some countries (such as Japan and Spain), the frequency of trains is decreased to control the number of travel passengers during the outbreak. On the contrary, the train frequency is increased to reduce the passenger loading rate of each carriage in some countries (such as China) during the resumption stage of working and production, which can not only guarantee the daily trips of citizens but also ensure the safety social distance of them. In addition, the transportation of emergency supplies and life necessities should be regarded as the top priority during the epidemic, which are planed preferentially and timely.

Alter transportation procedure. The epidemic disrupted the original travel plans of many passengers. For non-essential travel, most passengers will choose to apply for refunds. In fact, the government also encourages passengers to cancel travel plans and consciously isolate themselves at home. Therefore, corresponding measures have been introduced to facilitate passengers to go through such procedures. The specific measures can be changing the original booking rules, without handling fees. For rail transportation, passenger travel needs to be planned in advance, so the time limit for refunds can be extended and the scale of online ticket purchases needs to be expanded, providing convenience as much as possible. Some places updated the rules for ticket reservations, increased the reservation ratio and reassigned seats to ensure a safe distance between passengers. Besides, to improve the safety of rail transit system, the closed counters were used and contactless ticket sales were recommended.

Strengthen cooperation. To improve the service level of rail transit system, the joint efforts of the whole society are necessary, instead of the railway industry alone. The rail transportation departments of countries all over the world are exploring the new cooperation models with other industries. For instance, working with the human resources agency, which will assess the impact of human losses on the transportation system so that production can be returned to normal as soon as possible when the outbreak recovers. The medical department will provide convenience for emergency delivery to infected people and get access to the latest information on the virus timely. In return, the rail transit industry can also help them by exclusive services, such as customized trains and parking lots. Cooperating with the police could place the station under control, ensure the channelization of passengers and maintain the order of transportation, which are widely used in France, Germany and China.

\section{Evaluation Of The Countermeasures}

To analysis the effectiveness and acceptability of the researched countermeasures, a set of evaluation indicators were proposed, which can be used to compare the advantages and disadvantages of the countermeasures. The applicable scenarios of different measures should also be discussed to provide suggestions for the epidemic prevention of the rail transit system in various countries during the epidemic period.

\subsection{Determination of evaluation architecture}

From the above classification of different countermeasures, the implement objects of them include people, equipment and information. To evaluate the consequent of these methods, the evaluation architecture will be established as three aspects, which is shown as follows.

\subsubsection{For people}

The management of passengers and staff can reflect the implement consequence of the policy through a series of phenomena. Within a certain range of expenditure, adopting safe, valid and convenient measures can improve the operation efficiency of rail transit. Therefore, the evaluation indicators focus on the epidemic prevention, disposal of suspected cases and staff control in this part. Six indicators Effectiveness, Economic efficiency, Acceptability, Privacy, Comfortableness, Convenience are proposed, and the concrete meaning of them will be discussed in detail as follows:

Effectiveness. Whether the epidemic prevention measures can prevent the spread in the implementation process is one of the most important indicators in the evaluation architecture. If these measures can prevent the spread of the epidemic at the source, they will play a crucial role in the prevention of the epidemic. In this indicator, the control of external passengers should be considered, as well as the management of internal staff. Specifically, this indicator is used to evaluate the effectiveness of controls on passengers and the effectiveness of internal management measures. It can be regarded that whether the measure taken can hold passengers' and staffs' social distance in a safe range, whether the provided services can ensure the safety of passengers and staffs to avoid being infected, whether the measures of COVID-19 suspected cases disposal can reduce the release and diffusion of the virus, and whether the internal management measures can avoid the virus transmission between the employees.

Economic efficiency. It is necessary to consider the cost of these measures. In the special period, some measures regardless of the cost have been implemented in some countries, especially where the railway sector is controlled by the government, but it has always been an important consideration for 
some countries with private railway companies. The economic efficiency includes not only the cost of hiring more people and using more equipment, but also the loss of benefits due to the restrictive measure.

Acceptability. For passengers and staffs, the epidemic prevention measures should be acceptable. Excessive measures may cause panic among the public, so the measures should be reasonable and easy to be accepted by the public.

Convenience. Affected by the epidemic, a lot of measures have been added to the daily management. These measures will have an impact on the convenience of passengers' travel, some are severe and others are weak. Therefore, the convenience for passengers should be taken into account, which is mainly aimed at the measures that related to the passengers. What's more, whether the measures increase the work load of employees, should also be considered.

Privacy. The passengers are required to take mask and take temperature and the suspected cases are required to be isolated and notified to the public when they have a travel by rail transit system, which may involve the privacy of the passengers or staffs. Excessive measures may lead to an invasion of the privacy of passengers or staffs. Even in a period of widespread epidemic, people hope their privacy will be protected as much as possible. Therefore, privacy is one of the evaluation indicators.

Comfortableness. The comfortableness or the service level has always been one of the most important evaluation indicators in the public transit system. Some epidemic prevention measures may bring better travel experience for passengers, such as space between seats, which may provide more space for passengers. On the contrary, some measures may affect the comfort of passengers, such as taking temperature frequently, wearing masks and so on, especially when passengers are not will to follow the advice. Therefore, although it is a special time, the comfort of passengers should be considered.

\subsubsection{For equipment and operation}

The evaluation of the equipment and operation management should focus on the mitigation of virus transmission after the implementation of the measures. Meanwhile, the feasibility of the measures, and the economic efficiency of them, as well as the impact on the passengers' travel and their own operations should also be considered. Therefore, six indicators are proposed for equipment and operation management measures. They include the above four indicators (Effectiveness, Economic efficiency, Acceptability, Convenience) that have been introduced, and two new indicators (Operability, Disturbance) that will be discussed as follows.

Operability. The epidemic prevention measures need to be both effective and operational. The indicator is used to evaluate the difficulty of the measures operating. The measures that are easy to implement are more conducive to prevent and control the epidemic. Whether additional equipment and training are required or not. Whether these measures require additional staff and whether there are professional requirements for these staff.

Disturbance. Under the daily operation plan, the additional epidemic prevention measures may disturb the implementation of the plan. Therefore, the impact of the internal measures on the equipment management and operation plan should be considered in the evaluation architecture.

\subsubsection{For information}

Due to the particularity of information dissemination, the evaluation of that will be discussed individually from other point of views, such as the influence, scope, recognition and timeliness. Specifically, four new indicators (Timeliness, Pervasiveness, Validity) will be discussed as follows. Meanwhile, the proposed indicators Economic efficiency $\square$ Acceptability and Disturbance should also be considered to evaluation the measures of information dissemination.

Timeliness. The timeliness of information is one of the most important evaluation indicators for information dissemination. It indicates whether the message can be timely updated and published. The real-time updates of information can provide travelers with great travel decisions.

Pervasiveness. The extent to which information spreads is also worth to discuss. The more widely the information is spread, the more people are likely to receive it and the better the prevention will be.

Validity. The influence of information on passengers reflects the behavior of passengers after obtaining the information. If the information is valid and the measures are feasible, the passenger will accept the advice of the information. Otherwise, the passenger will continue to follow his/her own habits.

\subsection{Evaluation and comparison}

Based on the classification in Section 3, the countermeasures are evaluated by the above proposed indicators. A questionnaire including the above countermeasures and indicators was made for the respondents to evaluate. The respondents evaluated each method under different indicators by scoring 1 to 6 based on their own views of the COVID-19 transmission and railway response. The score of 6 means that the method did pretty well on this indicator, in which the result tends to be worse with the score decreasing, until the score equals to 1 , which indicates that it has a negative effect under this indicator. We analyzed the data collected from the investigation, and the evaluation results are reflected in the radar charts. As shown from Fig 4 to Fig 10 , every closed loop represents a countermeasure, which is formed by the value of each evaluation indicator. If the point is located on the periphery of the radar chart, it indicates that the measure gets a high score and reflects the indicator characteristic well; otherwise, it means the measure gets a low score and has disadvantages under this indicator. What's more, the countermeasures are compared in the same classification, and the advantages and disadvantages of them are discussed separately.

\subsubsection{Evaluation on passenger management countermeasures}

(1) On board 
As shown in Fig 4, the service management countermeasures on board are evaluated from 6 aspects.

In terms of effectiveness, the measures such as taking personal protection, taking temperature and improving disposal waste process may be beneficial. Specifically, taking personal protection is efficient when the passengers are exposed to the public areas for a long time. The passengers are suggested to take masks, use disinfectant and wash hands frequently in the public. It should be noticed that some passengers' disposable protective equipment may be reused more than once, which may not isolate the virus and also not conducive to the guarantee of healthy. The correct behavior is to replace the disposable mask at a fixed frequency and the replacement frequency is implemented in accordance with the regulations of the manufacturer, such as replace it per 6-8 hours or use a mask only within one trip. Randomly taking temperature on board for passengers can find the people who have a fever and maybe have been infected, which could take measures timely such as isolation and ensure the system in a virus-free (or healthy or clean) state all the time. At the same time, combined with improving disposal waste process may cut off possible transmission of the virus inside the train and limit its potential for spread to the outside. In comparison, the measures such as adjusting catering service may only achieve the goal of protection conditionally. The prohibition use of dining car may reduce the transmission of the virus effectively, but the measure may too harsh especially for the passengers with a long-distance trip. Packaging the food for passengers may avoid gathering to eat in the dining carriage, but the respiratory tract of passengers may also loss the protection and the infected possibility may increase, because the passengers have to take off their masks while eating.

From the perspective of economic efficiency, taking temperature and personal protection can be good choice. The former is less costly and more effective than other measures because it can control the virus spread at the source. The later can reduce the reserves of rail transit for protective supplies, so it has a reduction in economic expenditure. However, the adjustment of catering service, controlling loading rate and offering health necessaries shouldn't be recommended when considering the economic efficiency. The rail transit system is no longer to gain profits from the sale of meals and goods during the outbreak when the food service is prohibited. Loading rate control means the wasting of traffic capacity and the increasing cost of rail transportation, which may lead to a negative impact on the profits of operators. What's more, the offering of health necessaries may expend a lot of extra cost for operating.

From the perspective of acceptability, improving disposal waste process and controlling loading rate can be promoted. Disposing waste properly only requires necessary protection without excessive technical requirements and loading rate control can also be achieved by limiting passenger crowding, entering station by reservation or restricting number of tickets on sale. Therefore, the implementation of the above two measures is not difficult. However, the measures such as adjusting catering service and requiring personal protection will make passengers feel outrageous. Meals are inevitable for passengers, especially in a longdistance trip. And given that different passengers have different attitude to the epidemic, as well as the weather, some passengers may refuse the strict personal prevention for COVID-19.

Considering convenience and comfortableness factors, controlling loading rate has a better representation. As reducing the number of passengers on board and at station, it may provide seats with large interval and shorten part of the time for buying tickets and taking carriage, thus increasing the comfortableness of passenger travel. At the same time, it can also reduce the density of people in public places and increase standing area per capita, making the travel environment more friendly. However, passengers may not be able to board the train successfully due to the limited loading during peak hours. Therefore, it is recommended that the passengers should avoid or reduce travelling during the outbreak phase. By contrast, relying on personal protection solely may increase the complexity of passenger travelling. If passengers forget to wear masks, they will not be allowed to take the train, which may cause discomfort to some passengers. Requiring passengers to discard their garbage properly in accordance with regulations will also limit the freedom of passengers, which may increase the discomfort to the passengers more or less.

From the perspective of privacy, personal information includes the identity information, travel data for passenger and the staff work record at the same time. Among the several measures involved, controlling loading rate is the least information-gathering from passengers. Other measures may violate the privacy of passengers more or less. In the era of information interconnection, passengers' and staffs' information should be divulged outside of the transportation process as little as possible. The information should be deleted if no infection is found, when the incubation period of the virus is over.

In summary, most of the above measures have positive significance in ensuring virus free for rail transit system. Especially for taking personal protection, taking temperature and controlling loading rate, they are considered as the most effective measures to do, but they will also bring inconvenience to passengers or decline profits for enterprise respectively.

(2) At station

The countermeasures that taken on the station to cope with the COVID-19 are evaluated and the results are shown in Fig 5.

For effectiveness reason, the measures such as investigating qualification for passengers and closing public places are good ways. Passengers with fever and cough will not be able to enter into the station, so it can ensure that most of the passengers of rail transit service are healthy, which can control the virus spread at the source. In this case, it is almost impossible for the COVID-19 to spread in a closed carriage. To avoid the special emergency situation (such as the suspected cases were found by temperature screening), the passengers are still not encouraged to take off their masks. The closure of restaurants and shops reduces the possibility of passengers staying and gathering in public area, which can also reduce the spread of the virus effectively.

From the perspective of economic efficiency, providing travel advice have a better effect because it doesn't require the extra expending of operators. However, it may reduce the income of the operation in a long-term, because passengers are suggested to have less travel during the outbreak. Meanwhile, it is necessarily knowing their travel behavior and protect passengers' personal information, when the measure is applied. In comparison, closing public places and suspending ticket check are not advisable. The closure of restaurants and shops deprives them of a source of income and reduces the attractiveness of rail transit for passengers at the same time. Suspension of the ticket checking may increase the risk of passengers evading tickets and is not conducive to the revenue accounting of rail transit. Therefore, most of the measures may have a negative effect on the economic efficiency of operators.

Page $11 / 19$ 
In terms of acceptability, convenience and comfortableness, the advantage of suspending ticket check is obvious and the disadvantages of closing public places is prominent. Ticket checking cancel reduces the crowd gathering and contact, improving passengers' passing efficiency, which is acceptable for passengers. It's more inconvenient for passengers to wait for the train without the public services such as stores and restaurants. The service of rail transit is reduced, which may affect the satisfaction of passengers in travel. They have to plan their time before travel to reduce their dwelling time in public areas.

Regarding passenger privacy, investigating qualification needs to be focused particularly. Due to the related cases have occurred from different cities, it is necessary to inquire the passengers' travel path before a few days. The specialized staffs are dedicated by the operators to analysis this information and delete them after a certain time to prevent the spread of malicious.

Overall, investigate qualification before entering the station is the most effective way in these methods, but it is difficult to be accepted by passengers and may make passengers feel troublesome. The measure such as suspending ticket checking is the most acceptable measure for passengers, but the effectiveness and economic efficiency of the measure should be further strengthened by reasonable guidance and supervision.

\subsubsection{Evaluation on COVID-19 suspected cases care countermeasures}

The countermeasures that response for the COVID-19 suspected cases are evaluated and the results are shown in Fig 6.

From the perspective of effectiveness, we can know that keeping the suspected case taking masks and setting up temporary isolation area are valid measures. For confirmed cases and suspected cases, they have already appeared symptoms such as fever and cough, which need to be isolated immediately. To prevent the spread of the virus, keep all cases and close contacts wearing masks is one of the most effective and safest measures, thus it is mandatory. However, the process of transferring suspected cases is dangerous, because the virus may spread if it is leaked. Therefore, the effectiveness of transferring suspected cases is not obvious.

When evaluated by the economic efficiency, recording and tracing close contacts works well. The tracing measures are taken in time before the close contacts leave the rail transit system, in which the close contacts can be recorded quickly. The large-scale personnel inspection that prevents the virus spreading through the close contacts can be avoided in the future, which may consume a lot of material and financial resources. Transferring suspected cases is not a money-saving method. When the suspected cases are transferred, the staff must be fully protected by protective clothing and prepare a specific passage for transferring, which may increase the cost of operation.

Most of the measures are not perform well in the indicators of comfortableness, convenience, privacy and acceptability. In face of the COVID-19 cases, the primary task is to ensure the healthy by cutting off the virus transmission route, so the comfort and convenience of passengers may no longer be the first consideration. Meanwhile, it is indispensable to record and trace the information of close contacts, which will involve a large number of personal privacies, such as name and address. The personal privacy may also be invaded, which makes the passengers difficult to accept. Therefore, the measures adopt for the suspected cases should pay more attention on the feeling of passengers in the future. Rail transit operators shall protect the personal privacy during the information recording and reporting.

In general, most of the measures may affect the travel experience of passengers more or less, especially in the aspect of convenience, comfortableness and privacy. However, those measures are effectively to defeat the spreading of COVID-19, and the extra cost should also be invested more or less.

\subsubsection{Evaluation on information dissemination countermeasures}

The evaluation is carried out around three ways of information dissemination and the results have obvious characteristics, which are shown in the Fig 7.

From the perspective of pervasiveness, timeliness, acceptability and economic efficiency, the effect of TV and Internet are better than the other ways from almost all aspects. Nowadays, with the rapid development of technology, the time of releasing epidemic prevention information through TV or Internet is shorter and the scope of audience is wider. Moreover, people can access the news anytime and anywhere, which is not limited by time and space, so the effect is better under different evaluation dimensions. In contrast, presswork such as poster or other materials is not effective in the efficiency of information transmission, because the information that carries is limited. At the same time, the production process needs to consume a certain amount of time and the rail transit company needs to put into the design and printing costs. Since it can only be delivered manually, most passengers only can obtain the materials when travelling by rail. But some passengers lack patience to read that word by word due to their limited travel time, which also reduces the transmission efficiency.

In terms of validity and disturbance, the difference between the three measures has narrowed. Compared with other indicators, the implementation effect of internal mediums, posters and materials has been improved, mainly because they are generally set in eye-catching positions. The two indicators mainly describe the impact result of information on passenger travel, which has little relationship with how does the information spread in which way. As public health emergency of international concern, the COVID-19 interferes with daily life inevitably and passengers will take effective measures to respond for their own lives naturally.

In summary, release information by TV and internet is one of the most recommended measures for information dissemination, which can not only spread the information timely, acceptably, extensively, but also save the publicity cost. However, a notable question is the internet and TV may not widely used in some underdeveloped nations, so that measure is only suitable for the countries with mature network and communication systems.

\subsubsection{Evaluation on staff management countermeasures}

Fig 8 shows the evaluation results of the countermeasures about the staff management. 
From the perspective of effectiveness and acceptability, both strengthening staff protection and decentralizing staff distribution are worthy of reference. Strengthening protection can be required as a compulsory rule for the staffs, because they are managed by the enterprise uniformly. It can be regarded as their responsibility for the safety of themselves and passengers. Decentralizing distribution of staff is a feasible and effective measure to carry out. It is similar to loading rate control in service management, but the scenario is changed from the carriage to the office. Advising staff to stay at home in spare time is not a good choice in this view. Considering staff may need to deal with personal affairs in their free time, going outside is largely inevitable.

From the perspective of comfortableness and privacy, decentralizing staff distribution and encouraging remote communication can be further promoted. Although the lack of face-to-face work communication will cause obstacles to the connection of some work, especially for the transmission and filling of some documents with paper only. Remote communication is the most important way during the outbreak. Distributing staff will provide them with more personal space and the working environment will become better. In contrast, the effect of advising staff to stay at home in spare time is not satisfactory. Because it can restrict their freedom in their daily lives and make them feel uncomfortable inevitably. To achieve this measure, they may be forced to disclose some private information. Such measure should be avoided as far as possible unless the condition is very serious and must be done.

Under the indicator of economic efficiency, decentralizing staff distribution and restricting entry for regions are better. The two measures only changed the work scheduling and will not consume excess manpower and material resources. On the contrary, strengthening staff protection requires anti-epidemic supplies. What's more, if carrying out training for staff, they have to take extra time to learn the necessary knowledge and the company also needs to hire professionals to teach. Considering that different employees have different learning abilities, different employees in various positions should receive varies type of training.

Regarding the convenience of work, enhancing work flexibility reflects this very well. The measure can present the humanity of the enterprise and improve the company's care for staffs, especially for some people who are in poor physical condition, which significantly improves the comfort and convenience of work. Strengthening staff protection and advising staff to stay at home in spare time are not so good in this way. The main reason is that the epidemic will not end within a short period of time and daily working hours are long. It is difficult for staffs to work with protection and to stay at home during spare time for a long time.

From the above analysis, it can be seen that decentralizing staff distribution has the best effect under multiple indicators, but its shortcoming lies in the inconvenience caused by working handover. Meanwhile, the protection training and staff protection may necessary for staffs during the outbreak, which can make staffs to learn how to protect both the passengers and themselves, even it may cost some extra manpower and material resources.

\subsubsection{Evaluation on equipment management countermeasures}

As shown in Fig 9, the evaluation results of the countermeasures about the equipment management are discussed.

Considering effectiveness and convenience, the two measures can reduce the possibility of virus survival in the rail transit system. At the same time, they both require specialized staff to perform this work, which may increase the burden of staffs.

From the view of economic efficiency, the enterprises need to purchase special disinfection supplies and assign specific staffs to perform the disinfecting work, which require the funding. However, enhancing air circulation may consume more, because the air filter element needs to be replaced frequently and the ventilation equipment inside the train and the station need to be reformed to enhance the air circulation.

As for acceptability and operability, due to the technical requirements of enhancing air circulation, it can be carried out only when the company has corresponding technical staff. Therefore, the acceptability and operability of increasing disinfection frequency are higher than that of enhancing air circulation.

In summary, the performance of disinfection measures is better than that of ventilation measures form the most aspects expect the disturbance for operating, because some equipment cannot be used during disinfecting, the occupation of equipment requires a scheduling plan correspondingly, and it is also inconvenient for staffs to schedule. While, the ventilation and disinfection are both important parts no matter at the station or on the carriage. As an emergency public health incident, the COVID-19 epidemic is characterized by urgency, complexity, uncertainty and hazard. Although the measures may consume a certain cost, they are effectively to protect the system and avoid spreading of virus, which are necessary to apply during the outbreak.

\subsubsection{Evaluation on operation management countermeasures}

The operation management countermeasures are evaluated and the results are shown in Fig 10.

In the process of operation management, the disturbance on operating and the convenience of scheduling are important parts of evaluation. Strengthening cooperation may cause minimal disturbance to that. The positive significance of cooperation is that it can invite more professionals such as doctor and police to enhance the internal ability to prevent the COVID-19. Therefore, the disturbance may be better than the other two measures. When refunding or changing the tickets, it's inconvenient for passengers and need more extra time. Especially in countries where internet service is not widespread yet, people can only go to the manual window to complete the change.

In the four aspects of effectiveness, economic efficiency, acceptability and operability, the effects of the three measures are not much different and indicators of the three are not obvious. It is necessary to pay attention to prevent the spread of the virus caused by crowd gathering when altering transportation procedure with the high density of passenger. The measures taken under abnormal circumstances may affect the operating revenue of rail transit. Considering the barriers between different industries and the constraints of social environment, cooperation between different profession may have difficulties in implementation. 
In summary, the effect of adjusting operation plan is better because it can directly control the transit supply. The control of operating frequency may have a great effect on the prevent of virus spreading. During the outbreak, the operating frequency is decreased and the passengers are required to reduce their unnecessary trips. During the recovery, the operating frequency is increased to reduce the personnel density in the system. The passengers' trip has been impacted by the COVID-19 epidemic, so do the transportation schedule. During the epidemic, public transportation needs to provide a safe environment for the citizens. All countries need to control the scale of transportation according to local conditions. In fact, any measures should be implemented selectively according to the situation of social environment and national macro policies.

\section{Conclusion}

In this paper, the transmission ways of COVID-19 were summarized through the study to overview the low pathogenicity, medium transmission and aggregation characteristics of it. To prevent the spread of COVID-19 in public transport, the characteristics of closed rail transit carriages and passenger flowintensive attribute are analyzed. So that the importance of the control measures to deal with the epidemic in rail transit is emphasized to prevent the spread of the virus.

The countermeasures to reduce the spread of COVID-19 in rail transit system were introduced from the categories of the external management and internal management. The external management includes service management, suspected cases care and information dissemination measures, which increased the passenger entry control efforts, valued the response for the suspected cases, and adopted to control the spread of COVID-19 in the system from the source. The internal management includes staff, equipment and operation management, which can realize strict personnel management and facilities disinfection to prevent the spread of COVID-19. By classifying and summarizing of the countermeasures, an evaluation architecture that includes 11 indicators is proposed to evaluate every measure from 6 aspects and compare with others in the same category. Afterwards, some suggestions are put forward for countries to better respond to COVID-19.

In summary, most of the above measures have positive significance in prevent the virus for rail transit system, but the extra cost should also be invested more or less. There are some measures that are both efficient and cost-effective, such as take personal protection, take temperature, decentralize staff distribution, encourage remote communication, release information by TV and internet, which should be recommended to the rail transit operators all over the world. Meanwhile, there are some measures that considers more about the travel experience of passengers and working experience of staffs, such as control loading rate, suspend ticket checking, encourage remote communication, enhance work flexibility, which also want to be accepted by the employers. However, there are some measures that are very efficient but may severely affect the experience and privacy of travelers and employees, such as investigate qualification, report suspected case, record and trace close contacts. During the outbreak period, especially the number of infected rises explosively, those measures should be considered firstly, because the primary task of the operators is to ensure the health of passengers and the comfort and convenience of passengers may no longer be the first consideration. While, those measure should be taken with caution during the recovery.

A sudden public safety incident is a great test of the ability of the public transportation industry, including rail transit, to adapt in a timely manner. This outbreak is a wake-up call for the rail transit operators in the prevention of emergencies, emergency planning, emergency response and other aspects. Only by comprehensively considering all kinds of situations that may occur in traffic, including the spread of the epidemic, can we prevent the situation before it occurs, improving the emergency response ability and providing guarantees for the normal operation of the society.

\section{Declarations}

Competing interests: The authors declare no competing interests.

\section{References}

[1] International Ebola Response Team, Junerlyn A, Archchun A, et al (2016) Exposure patterns driving Ebola transmission in West Africa: a retrospective observational study. PLoS Med. https://doi:10.1371/journal.pmed.1002170

[2] Kramer AM, Pulliam JT, Alexander LW, et al (2016) Spatial spread of the west Africa Ebola epidemic. R Soc Open Sci. https://doi:10.1098/rsos.160294

[3] Colizza V, Barrat A, Barthélemy M, Vespignani A (2006) The role of the airline transportation network in the prediction and predictability of global epidemics. Proc Natl Acad Sci USA. https://doi:10.1073/pnas.0510525103

[4] Zhao S, Zhuang Z, Ran J, et al (2020) The association between domestic train transportation and novel coronavirus (2019-ncov) outbreak in China from 2019 to 2020: A data-driven correlational report. Travel Med Infect Dis. https://doi:10.1016/j.tmaid.2020.101568

[5] Tirachini A, Oded C (2020) COVID-19 and public transportation: current assessment, prospects, and research needs. J Public Trans. https://doi.org/10.5038/2375-0901.22.1.1

[6] Zheng R, Xu Y, Wang W, et al (2020) Spatial transmission of COVID-19 via public and private transportation in China. Travel Med Infect Dis. https://doi:10.1016/j.tmaid.2020.101626

[7] Chu DK, AkI EA, Duda S, et al (2020) Physical distancing, face masks, and eye protection to prevent person-to-person transmission of SARS-CoV-2 and COVID-19: a systematic review and meta-analysis. The Lancet. https://doi:10.1016/s0140-6736(20)31142-9 
[8] Hu M, Lin H, Wang J, et al (2020) The risk of COVID-19 transmission in train passengers: an epidemiological and modelling study. Clin Infect Dis. https://doi: 10.1093/cid/ciaa1057

[9] Chen J (2020) Pathogenicity and transmissibility of 2019-nCoV-A quick overview and comparison with other emerging viruses. Microbes Infect. https://doi.org/10.1016/j.micinf.2020.01.004

[10] Centers for Disease Control and Prevention (2020) Social distancing.

https://www.cdc.gov/coronavirus/2019-ncov/prevent-getting-sick/social-distancing.html. Accessed 15 July 2020

[11] Niu L, Liang W, Wang X, et al (2020) Analysis of factors affecting the survival of viruses on the surface of objects and in the air. Environmental Science Research. https://doi.org/10.13198/j.issn.1001-6929.2020.05.37

[12] Feng X, Wang Y, Liu S, et al (2020) The impact of the COVID-19 outbreak on urban rail transit operations. Transportation Research. https://doi: 10.16503/j.cnki.2095-9931.2020.01.006

[13] International Union of Railways (2020) 20200403_UIC Covid19 TF_Data Base.

https://extranet.uic.org/,2020. Accessed 3 April 2020

[14] United Nations International Children's Emergency Fund (2020) Everything you need to know about washing your hands to protect against coronavirus (COVID-19).

https://www.unicef.org/coronavirus/everything-you-need-know-about-washing-your-hands-protect-against-coronavirus-covid-19. Accessed 13 March 2020

[15] Shenzhen Hongxiangwen Hook \& Loop Co., Ltd (2020) How long can a disposable face mask last?

https://www.hxwsports.com/industry-information/how-long-can-a-disposable-face-mask-last-

22600/\#: :text=Disposable\%20face\%20mask\%20is\%20not\%20reusable.\%20Generally\%2C\%20they,inner\%20layer\%20blocks\%20the\%20exhaled\%20bacteria\% Accessed 9 April 2020

\section{Figures}

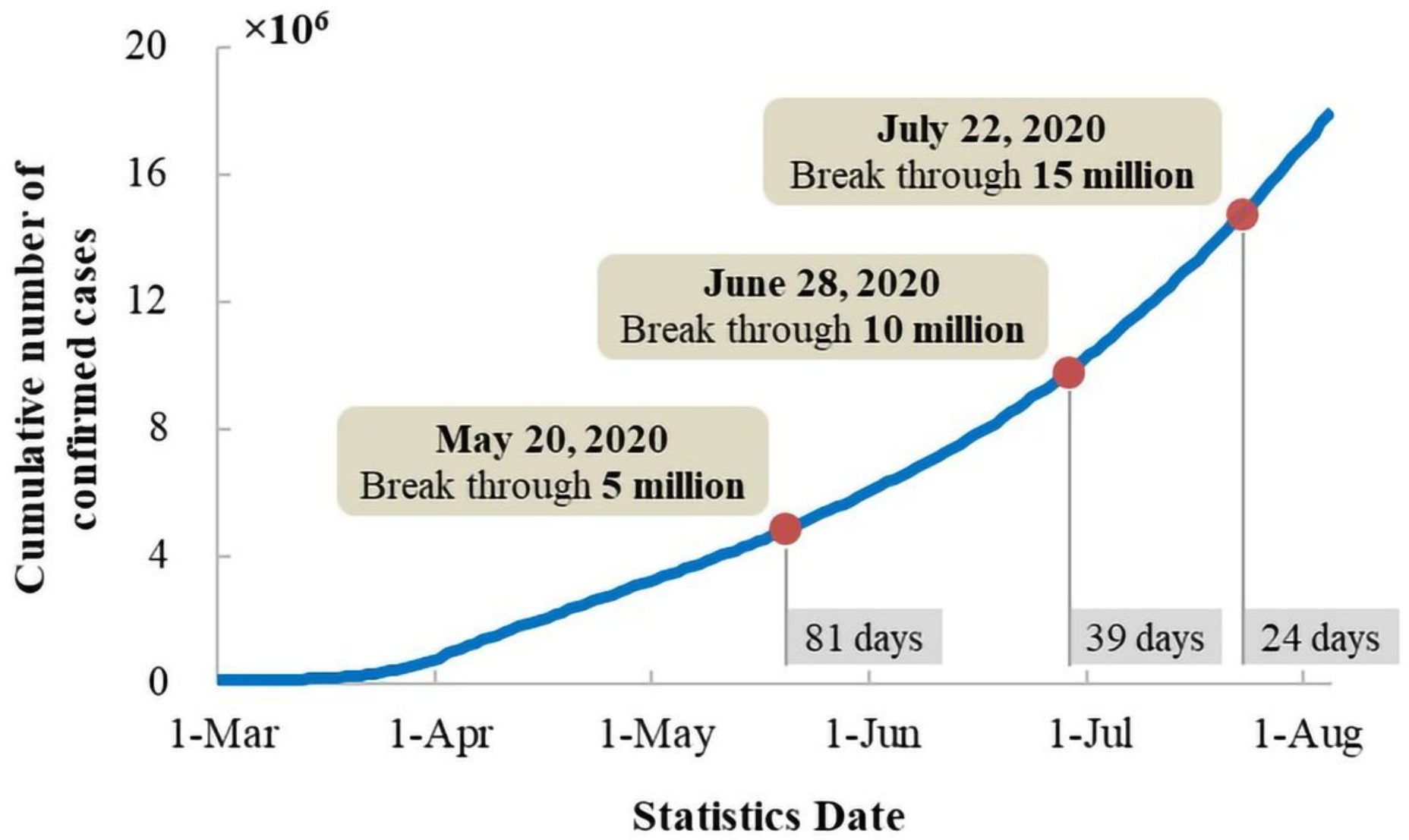

Figure 1 


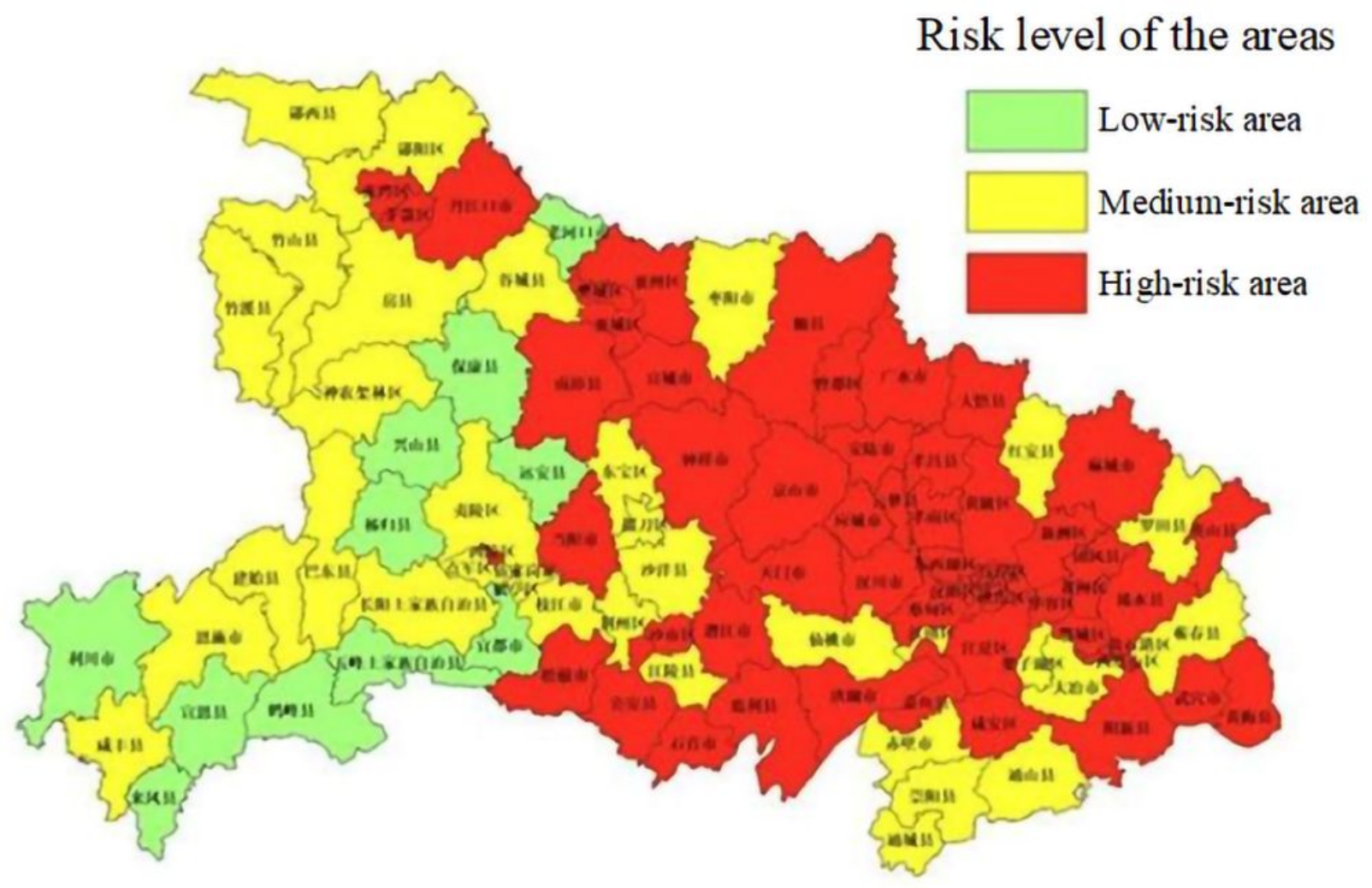

Figure 2

The risk level of the areas in Hubei province of China on February 28, 2020 Note: The designations employed and the presentation of the material on this map do not imply the expression of any opinion whatsoever on the part of Research Square concerning the legal status of any country, territory, city or area or of its authorities, or concerning the delimitation of its frontiers or boundaries. This map has been provided by the authors.

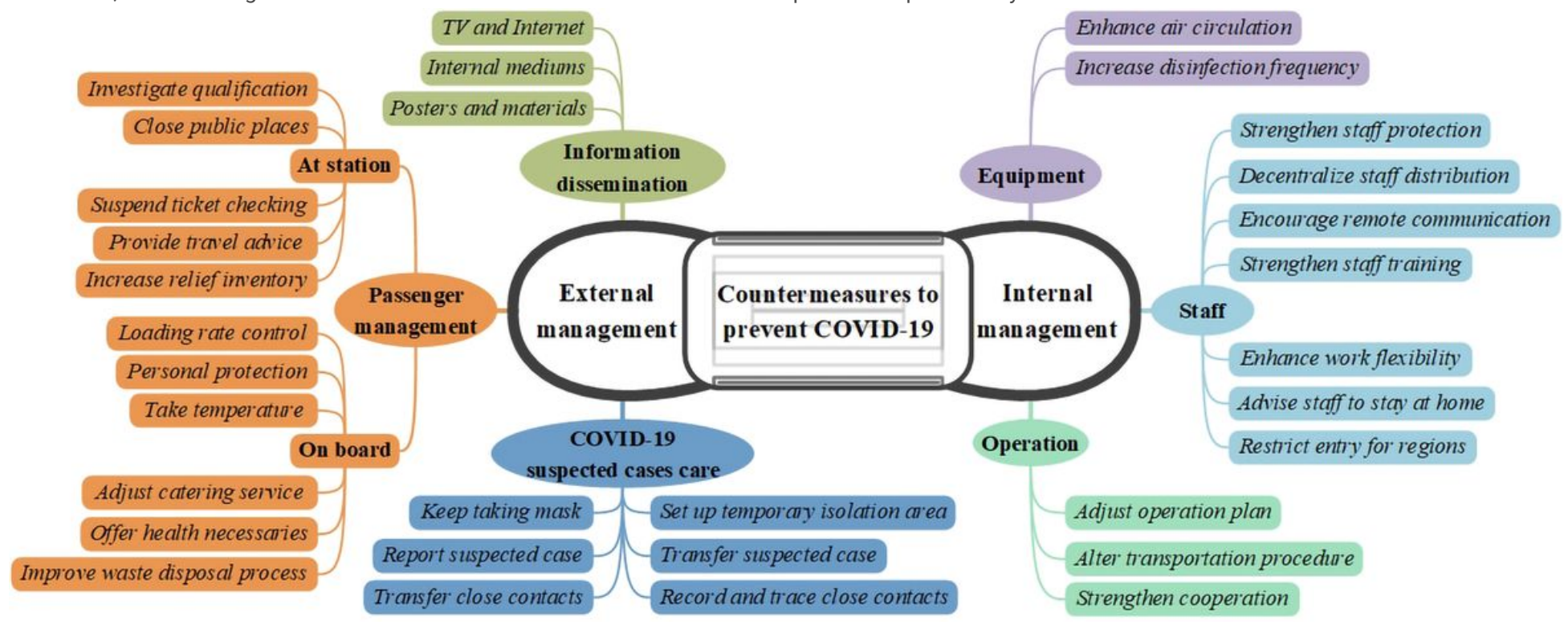

Figure 3

Outline of initiatives to prevent the COVID-19 for rail transit 


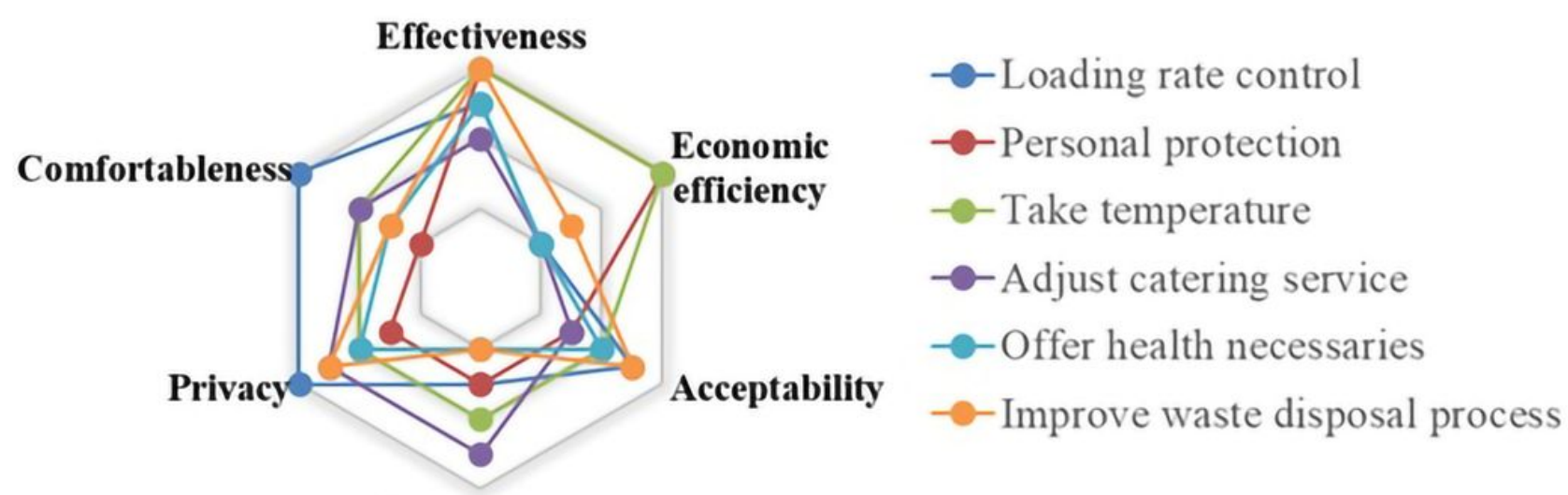

Convenience

Figure 4

Evaluation results about passenger management on board

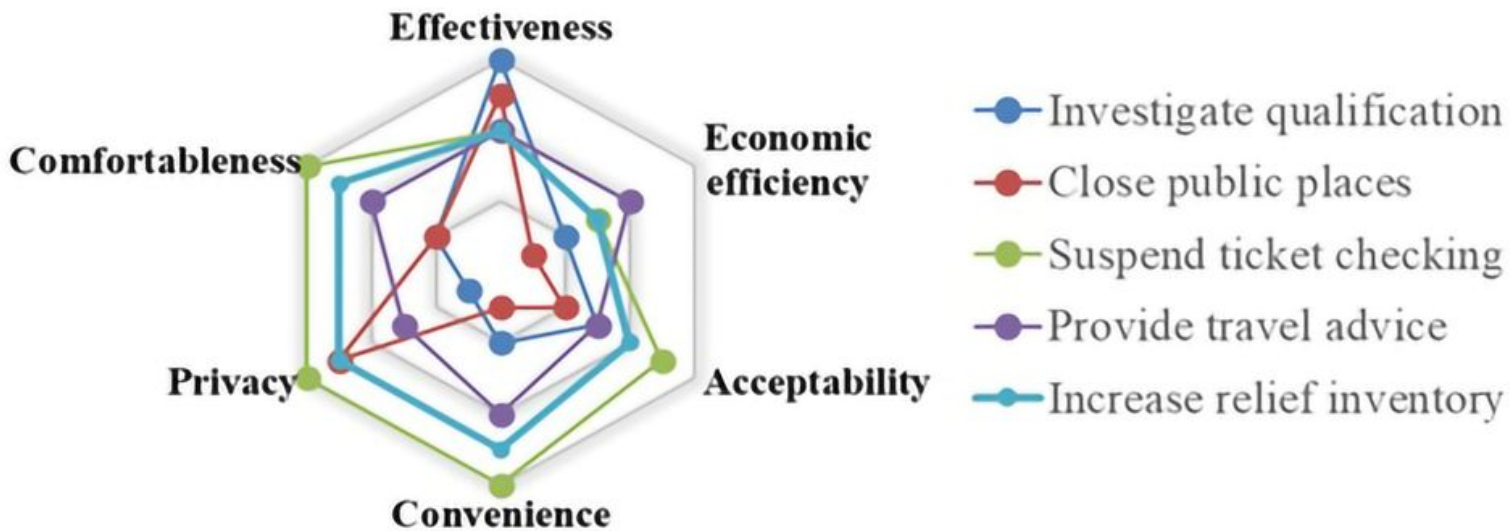

Figure 5

Evaluation results about passenger management at station

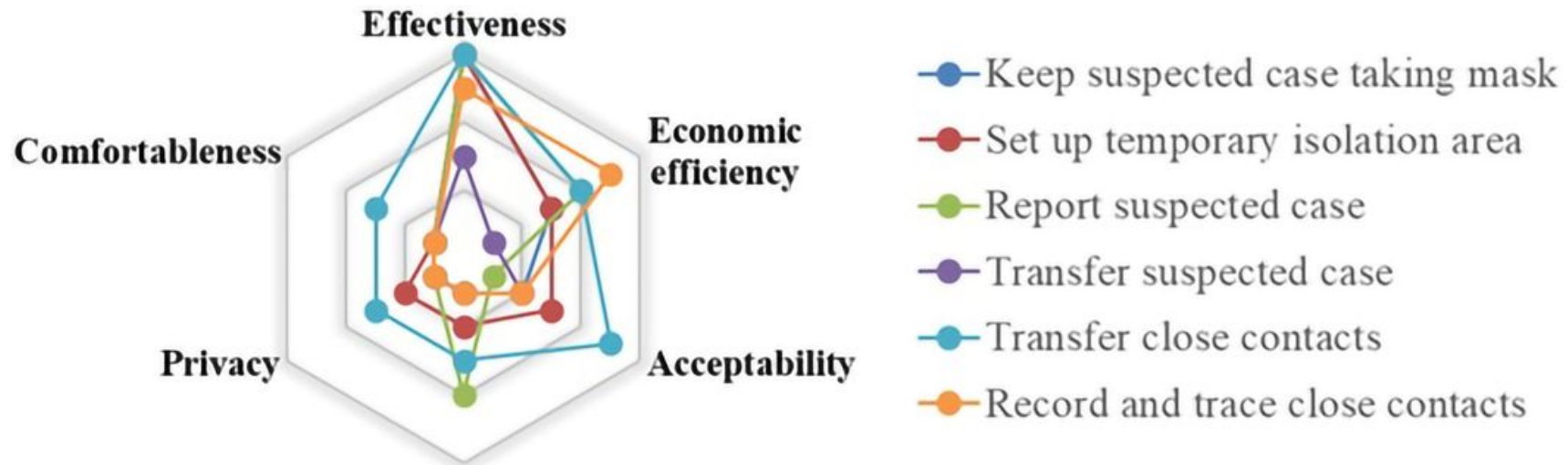

Convenience

Figure 6

Evaluation results about COVID-19 suspected cases disposal 


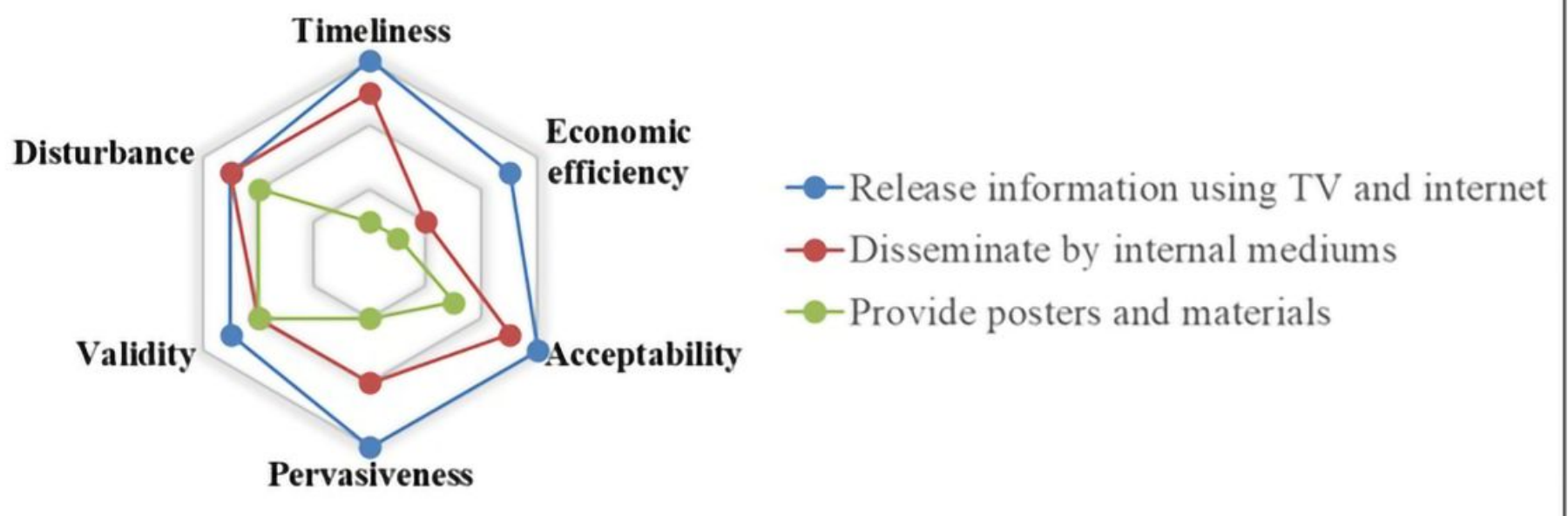

Figure 7

Evaluation results about information dissemination

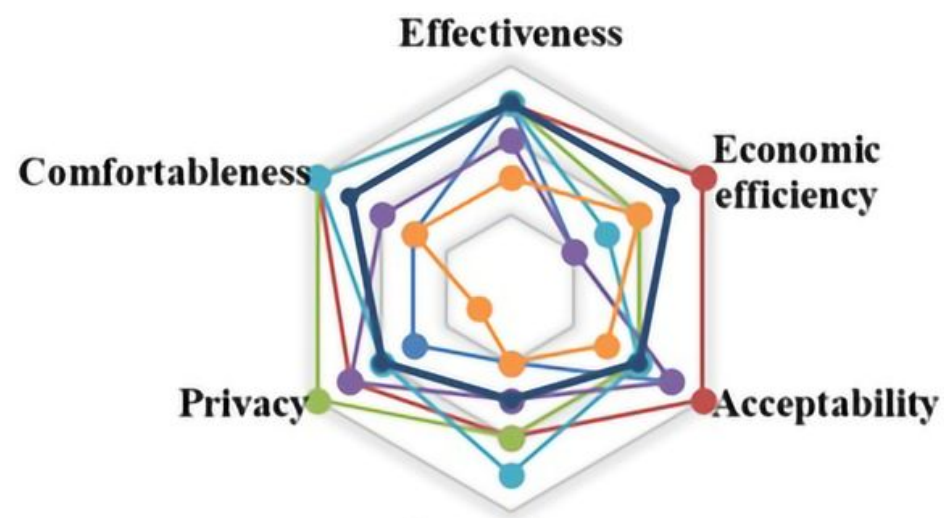

- - Strengthen staff protection

- -Decentralize staff distribution

- Encourage remote communication

- Strengthen staff training

- - Enhance work flexibility

- - Advise staff to stay at home in spare time

$\rightarrow$ Restrict entry for regions

\section{Convenience}

Figure 8

Evaluation results about staff management

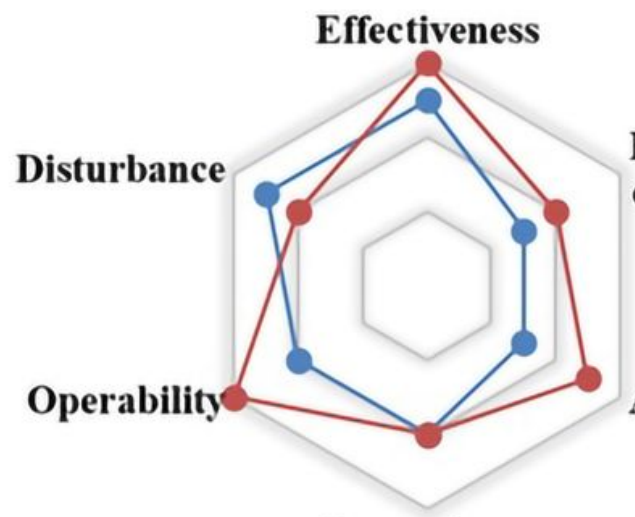

Economic efficiency

- -Enhance air circulation

- Increase disinfection frequency

Acceptability

\section{Convenience}




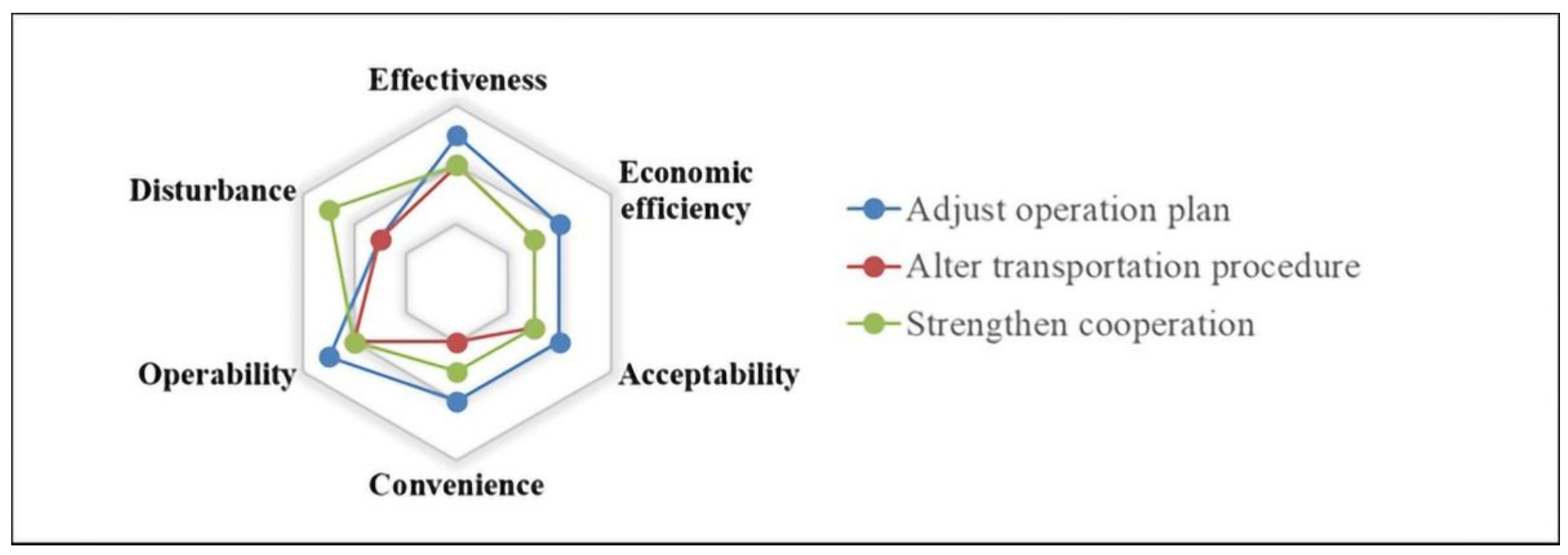

Figure 10

Evaluation results about operation management 